\title{
DATA VISUALIZATION OF INTERNET USAGE IN THE JABODETABEK AREA
}

\author{
Evaristus Didik Madyatmadja ${ }^{1}$, An Nisa'a Nuramalia ${ }^{2}$, Lusi Kusumawati ${ }^{3}$, \\ Syahlaa Perdina Jamil ${ }^{4}$, Wahyu Kusumawardhana ${ }^{5}$ \\ 1,2,3,4,5 Sistem Informasi \\ 1,2,3,4,5 Universitas Bina Nusantara, Jakarta, Indonesia \\ Correspondence email: emadyatmadja@binus.edu
}

Article history: $\quad$ Submission date: Juni 27,2021 Revised date: Juni 28, $2021 \quad$ Accepted date: Juni 30, 2021

\begin{abstract}
The purpose of this study is to analyze and visualize internet usage data in the Jabodetabek area for the last 3 years, namely 2017, 2018, 2019 using quantitative methods which will display data per city and per year which is processed into the percentage of internet usage in the area. In addition, we also used the $K$-means clustering method as a method of grouping data and we chose to use the age variable for analysis. Along with the development of information technology, governments in various regions have also begun to expand the circulation of the internet to broaden people's insights and disseminate information more easily. However, in the current situation and conditions, it is felt that the distribution of internet use, especially in the Jabodetabek area, is still not optimal. Even though the area is a metropolitan city as the center of urban community activity. Therefore, through data on the percentage of Jabodetabek areas that access the internet, it can be seen as one of the factors for the government to be able to increase the performance of the internet evenly. The data will be visualized using the Tableau application in graphical form to facilitate information delivery to users in reading the results of data analysis.
\end{abstract}

Keywords: Data visualization, Internet Usage, Jabodetabek

\begin{abstract}
ABSTRAK
Tujuan dari penelitian ini adalah untuk menganalisis dan memvisualisasikan data penggunaan internet di wilayah Jabodetabek selama 3 tahun terakhir yaitu 2017, 2018, 2019 menggunakan metode kuantitatif yang akan menampilkan data per kota dan per tahun yang diolah menjadi persentase penggunaan internet. di daerah. Metode yang digunakan K-means clustering sebagai metode pengelompokan data dan kami memilih untuk menggunakan variabel usia untuk analisis. Seiring dengan perkembangan teknologi informasi, pemerintah di berbagai daerah juga mulai memperluas peredaran internet untuk memperluas wawasan masyarakat dan menyebarkan informasi dengan lebih mudah. Namun dalam situasi dan kondisi saat ini, dirasakan distribusi penggunaan internet khususnya di wilayah Jabodetabek masih belum optimal. Padahal kawasan tersebut merupakan kota metropolitan sebagai pusat aktivitas masyarakat perkotaan. Oleh karena itu, melalui data persentase wilayah Jabodetabek yang mengakses internet dapat dilihat sebagai salah satu faktor pemerintah untuk dapat meningkatkan kinerja internet secara merata. Data tersebut akan divisualisasikan menggunakan aplikasi Tableau dalam bentuk grafik untuk memudahkan penyampaian informasi kepada pengguna dalam membaca hasil analisis data.
\end{abstract}

Kata Kunci: Visualisasi Data, Penggunaan Internet, Jabodetabek

\section{PENDAHULUAN}

Di era yang semakin maju membuat teknologi ikut terus berkembang. Dengan kondisi seperti ini, kita menjadi lebih mudah untuk menjalankan kehidupan sehari - hari, seperti mudahnya berkomunikasi dengan kerabat yang berada di dalam negeri maupun luar negeri, hingga dimudahkannya mengakses dan mengolah data jumlah penduduk di suatu negara. Salah satu penunjang teknologi yang terus maju ini yaitu sistem informasi.

Sistem informasi adalah sistem yang menyediakan informasi dengan cara sedemikian rupa sehingga bermanfaat bagi penerima (Herliana, A., \& Rasyid, P. M. (2016, 2016). Sistem informasi ini merupakan gabungan antara teknologi informasi, manajemen dan juga manusia yang bekerja untuk menciptakan sebuah inovasi baru maupun mengembangkan teknologi yang sudah ada. 
Internet merupakan salah satu komponen yang memiliki peranan penting untuk sistem informasi. Di masa kini, kata "internet" sudah tidak asing lagi didengar. Internet adalah jaringan komputer yang menghubungkan satu komputer dengan komputer lainnya yang ada di seluruh dunia dengan kaya akan informasi didalamnya (Kristina, 2015). Dengan kekayaan informasi yang tersimpan inilah yang membuat internet telah digunakan oleh masyarakat di berbagai kalangan penjuru dunia, salah satunya Indonesia.

Berdasarkan data Asosiasi Penyelenggara Jasa Internet Indonesia (APJII) pada tahun 2016, Indonesia sendiri memiliki 132,7 juta pengguna internet $(51,5 \%)$ dari total masyarakat Indonesia sebanyak 256,2 juta jiwa (Yusup et al., 2019). Dengan data tersebut, kita dapat menyimpulkan bahwa pengguna internet di Indonesia lebih banyak dibandingkan masyarakat yang belum menggunakan internet.

Tetapi, hal tersebut dirasa kurang sesuai dengan situasi dan kondisi pada masa sekarang. Hal ini dikarenakan sebaran penggunaan internet per provinsi pada kota - kota metropolitan yaitu Jakarta, Bogor, Depok, Tangerang, dan Bekasi yang masih belum maksimal, terutama daerah - daerah pinggiran. Sedangkan Jakarta merupakan ibukota Indonesia, kemudian Kota Bogor, Depok, Tangerang, dan Bekasi merupakan daerah penyokong dari ibukota. Seharusnya pemerataan internet di daerah tersebut harus dimaksimalkan.

Dari banyaknya data yang telah dikumpul agar bisa disimpulkan dalam bentuk visualisasi yang mudah dimengerti, data visualisasi adalah cara yang efektif. Menurut Statistical Analysis System (SAS) institute. Visualisasi data ditampilkan dalam bentuk gambar atau grafik (Abyadl et al., 2018). Dengan bentuk gambar dan grafik ini, data visualisasi tentunya memiliki fungsi untuk mengkomunikasikan data - data yang telah dikumpulkan agar penggunanya mudah untuk dipahami.

Kemudian, dalam penelitian ini kami menggunakan metode penelitian kuantitatif. Metode kuantitatif adalah sebuah metode dalam penelitian dimana data yang dikumpulkan dapat diukur melalui teknik statistik. Dengan metode kuantitatif, nantinya data per kota dan per tahun akan diolah menjadi persentase, kemudian divisualisasikan menggunakan aplikasi Tableau menjadi sebuah grafik.

Sehingga dari permasalahan yang ada dan metode penelitian yang telah dipilih, kami ingin melakukan penelitian penggunaan data visualisasi untuk memvisualisasikan data penggunaan internet, dimana penelitian kami hanya di lingkup Jabodetabek. Dengan adanya penelitian ini, kami berharap agar dapat membantu pemerintahan dalam pemerataan internet agar penggunanya rata, terlebih lagi Jabodetabek merupakan kota - kota besar atau yang biasa disebut dengan kota metropolitan yang ada di Indonesia.

Business Intelligence merupakan kumpulan dan serangkaian kegiatan atau tahapan untuk mengumpulkan data dan menganalisis data sehingga dapat digunakan untuk proses pengambilan keputusan yang lebih baik ketika proses pengambilan keputusan vital dalam bisnis perusahaan atau keputusan untuk memperoleh tujuan dari bisnis perusahaan (Arifin \& Sugiharto, 2013). Dengan menjalankan proses Business Intelligence untuk mendapatkan informasi tentang pertumbuhan pengguna internet di Indonesia, pemerintah bisa lebih mudah mendeteksi daerah mana yang perkembangannya terlalu lambat dan perlu untuk diperhatikan. Selain itu, penggunaan Business Intelligence ini juga bisa membantu pemerintah kita mengambil langkah ke depan untuk mengimplementasikan E-government di Indonesia.

E-Government adalah bentuk teknologi informasi dan komunikasi yang dimiliki oleh pemerintah guna memudahkan melakukan komunikasi antara government ke government (G2G), government ke citizens (G2C) (masyarakat luas), dan government ke pelaku bisnis (G2B) (Noveriyanto et al., 2018). Dengan diimplementasikannya E-Government ini, informasi yang didapat setiap harinya oleh pemerintah bisa tersimpan lebih rapi dan dapat digunakan untuk mendukung pengambilan keputusan sehingga pemerintahan akan berjalan lebih efisien.

Selain membantu jalannya pemerintahan, pemerintah juga bisa mempublikasikan hasil analisis informasi yang sudah didapat kepada masyarakat. Hal ini bisa menjadi sebuah langkah kedepan dalam hal transparansi informasi. Dengan adanya transparansi informasi tersebut, pengetahuan masyarakat akan jalannya pemerintahan akan meningkat dan tentunya tingkat kepercayaan masyarakat terhadap pemerintah juga akan meningkat.

Jabodetabek akronim dari Jakarta - Bogor Depok - Tangerang - Bekasi yang merupakan kota metropolitan Jabodetabek dengan wilayah administrasi DKI Jakarta, Kabupaten Tangerang, Kota Tangerang, Kota Depok, Kota Bogor, Kabupaten Bogor, Kota Bekasi, dan Kabupaten Bekasi. Daerah Jabodetabek yang mayoritas penduduknya sudah menggunakan internet dalam kesehariannya. Luas area Jabodetabek sebesar $1230.8 \mathrm{Km} 2$ yang terdiri dari dense urban dengan luas wilayah mencapai $1207.77 \mathrm{Km} 2$ atau $98 \%$ dari total luas wilayah Jabodetabek, dan daerah urban sebesar $22.03 \mathrm{Km} 2$ atau sebesar 2\% dari total wilayah Jabodetabek. Area jabodetabek adalah salah satu area megapolitan dengan luas area dense urban sebesar 98\% dari total luas area (Ariyanti, 2015). 


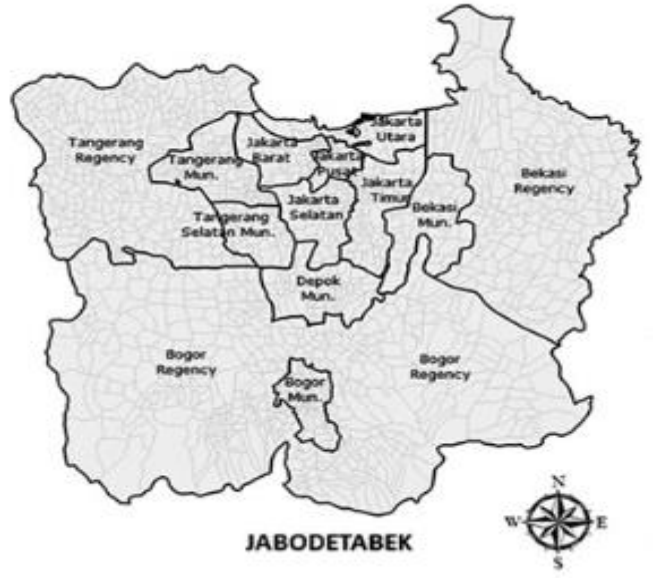

Sumber: (Evaristus Didik Madyatmadja et al, 2021) Gambar 1. Peta Jabodetabek

Wilayah Jabodetabek yang besar dengan perkembangan teknologi yang luas di Indonesia memberikan dampak terhadap penduduk sekitar untuk menggunakan jaringan internet. Internet dengan kecepatan tinggi dapat digunakan secara luas oleh penduduk. (Basis Data Pusat Pengembangan Kawasan Perkotaan, 2015). Dengan adanya internet yang digunakan, penduduk dapat menerapkan business intelligence yang berkaitan dengan penggunaan internet di Jabodetabek sehingga data pengguna internet ini dapat disebut dengan big data yang harus disimpan di sebuah penyimpan yang besar. Melalui big data yang sudah diolah dan dianalisis menjadi sebuah informasi akan bermanfaat untuk membantu pemerintah Indonesia dalam memutuskan sebuah keputusan dalam perkembangan Indonesia seperti Kominfo yang akan digunakan untuk mengetahui frekuensi penggunaan dan performa internet di daerah yang sudah stabil dan daerah yang kurang stabil (Rustiadi et al., 2015).

Data mining adalah suatu proses pengumpulan informasi penting dari suatu data yang besar. Proses data mining seringkali menggunakan metode statistika, matematika, serta memanfaatkan teknologi artificial intelligence. Banyak konsep dan teknik yang dapat digunakan dalam proses data mining. Teknik, metode, atau algoritma dalam data mining beragam. Pemilihan metode atau algoritma yang tepat sangat bergantung pada tujuan dan proses secara keseluruhan.

Nama lainnya, yaitu Knowledge Discovery (mining) in Database (KDD) atau knowledge extraction, pattern analysis, data dredging, dll. Dalam proses KDD tersebut terdapat langkah pembersihan data, integrasi data, seleksi data, transformasi, penambangan data, evaluasi pola, dan presentasi pengetahuan.

Data mining mempunyai fungsi utama, yaitu fungsi deskriptif dan fungsi prediktif. Fungsi deskriptif adalah fungsi untuk memahami lebih jauh tentang data yang diamati, diharapkan dapat mengetahui perilaku dari sebuah data tersebut. Data tersebut itu yang nantinya digunakan untuk mengetahui karakteristik dari data yang dimaksud. Fungsi predictive adalah fungsi bagaimana sebuah proses nantinya akan menemukan pola tertentu dari suatu data, pola tersebut dapat diketahui dari berbagai variabel pada data. Pola yang didapat bisa digunakan untuk memprediksi variabel lain yang belum diketahui nilai ataupun jenisnya. Selain itu, fungsi ini memudahkan dan menguntungkan untuk dapat memprediksi dalam membuat hal penting menjadi lebih baik. Jadi, data mining merupakan serangkaian proses untuk menggali nilai tambah dari suatu kumpulan data berupa pengetahuan yang selama ini tidak diketahui secara manual (Budiyantara et al., 2020).

Clustering menurut Berkhi adalah membagi data ke dalam grup-grup yang mempunyai objek yang karakteristiknya sama. Sedangkan, menurut Garcia clustering adalah mengelompokkan item data ke dalam sejumlah kecil grup sedemikian sehingga masingmasing grup mempunyai sesuatu persamaan yang esensial. Untuk itu, clustering adalah metode yang mengelompokkan data yang memiliki kesamaan karakteristik ke dalam kelompok yang lebih kecil. Clustering memiliki beberapa kategori yang dapat digunakan menurut Tan, yaitu hierarchical and partitional clustering. Hierarchical clustering adalah sekelompok cluster yang bersarang seperti sebuah pohon yang berjenjang/hirarki. Sedangkan, Partitional Clustering adalah pembagian objek-objek data ke dalam kelompok yang tidak saling overlap sehingga setiap data berada tepat di satu cluster (Asroni, 2015).

Metode clustering akan memproses untuk menemukan kelompok data yang bertujuan memperoleh pengelompokkan data dari dataset. Clustering akan klasifikasi tanpa pengawasan dan memproses partisi sekumpulan objek data dari satu set menjadi beberapa kelas yang dapat dilakukan dengan menerapkan berbagai persamaan dan langkah-langkah mengenai jarak algoritma, yaitu dengan menggunakan Euclidean Distance (Qolbi, 2016).

Rumus yang dapat digunakan untuk menghitung jarak dengan Euclidean Distance, yaitu :

Keterangan :

$$
\operatorname{Distance}(p, q)=\left(\sum_{k}^{n} \mu k|P k-q k| r\right) 1 / r
$$

$\mathrm{N}=\mathrm{Jumlah}$ record data

$\mathrm{K}=$ Urutan field data

$\mathrm{r}=2$

$\mu \mathrm{k}=$ Bobot field yang diberikan $u s e r$ 
$K$-means clustering adalah metode dalam data mining, dimana metode ini akan melakukan proses pemodelan tanpa supervisi, dan metode ini akan dilakukan pengelompokkan data dengan sistem partisi. Penggunaan $K$-Means ini nantinya akan meminimalkan variasi pada suatu clustering, serta akan memaksimalkan variasi data pada cluster lainnya (Rahmawati et al., 2016).

Istilah "Visualisasi data" dapat didefinisikan dalam beberapa cara. Sebagian besar definisi berfokus pada koneksi antara data dan teknologi komputer untuk mengubah data menjadi bentuk visual atau sonik. Proses dasar visualisasi data dalam bentuk apapun dapat diubah menjadi gambar grafis. Saat pengguna membaca atau melihat gambar grafis, gambar tersebut diinterpretasikan melalui sistem kognitif manusia untuk memperoleh wawasan atau pemahaman akan informasi yang berguna (Richard Qi Li, 2020).

Visualisasi data dapat menggambarkan relasi dan pola antara variabel yang ada dalam data. Para pengambil keputusan akan melihat koneksi antara data yang bersifat multi-dimensi. Tujuan pokok visualisasi data ialah untuk mengkomunikasikan informasi secara jelas dan efektif melalui sarana grafis. Visualisasi yang baik tentu terfokus, memberikan jawaban yang jelas, dan tidak terlalu detail.

Untuk mencapai visualisasi yang baik dilakukan proses visualisasi data, yaitu acquire meliputi proses pengambilan data baik dari internet maupun dari disk lokal. Parse merupakan proses memberikan struktur data yang tepat pada data yang akan diolah. Filter merupakan seleksi dengan menghapus data yang tidak penting atau tidak menarik. Mine meliputi proses melakukan analisis statistik atau data mining terhadap data untuk mencapai tujuan. Represent merupakan proses merubah data dan disajikan dalam bentuk model visual dasar seperti, grafik batang atau pohon. Refine merupakan model visual dibuat lebih jelas dan lebih menarik. Proses ini bersifat pilihan. Interact adalah proses merubah grafik status menjadi grafik dinamis agar data bias ditampilkan sesuai keinginan pengguna (Irmayani, 2021).

\section{METODE PENELITIAN}

Metode Penelitian ini berisi paparan dalam bentuk paragraf tentang rancangan penelitian, Tableau adalah perangkat lunak bisnis intelijen yang digunakan dalam pembuatan visualisasi data, analisis data, dan pelaporan yang mudah untuk digunakan (Saepuloh, 2020). Hal ini dikarenakan penggunaannya hanya dengan melakukan drag dan drop suatu bidang ke rak rak yang sesuai dalam pengkodean visual, seperti bentuk, warna, ukuran, dan posisi (Hartama, 2018).
Tableau juga dapat menggabungkan data seperti yang bersumber dari database, spreadsheet, big data, dan cloud data dalam satu program untuk dianalisis.

Untuk melakukan visualisasi data penggunaan internet di wilayah Jabodetabek, kami akan menggunakan aplikasi Tableau. Dalam pengolahan data agar bisa divisualisasikan, berikut arsitektur dalam Tableau (Center, 2015).

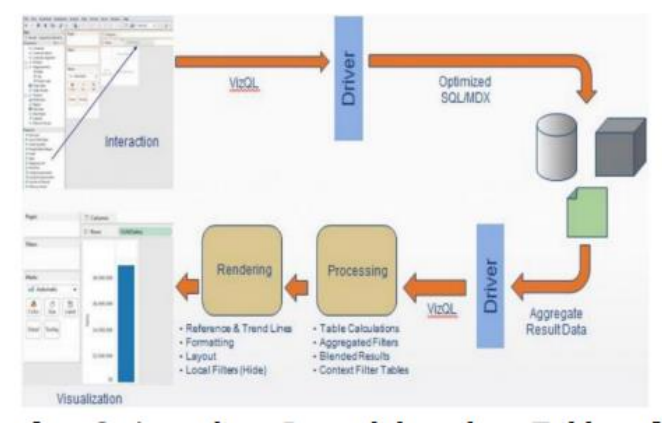

Gambar 2. Arsitektur pengolahan data pada Tableau

\section{Metode K-Means}

Metode K-Means adalah metode yang termasuk dalam algoritma clustering dengan berbasis jarak yang membagi data ke dalam sejumlah cluster yang hanya bekerja pada atribut numerik. Pengelompokan data dengan metode K-Means dilakukan dengan cara sebagai berikut:

1. Menentukan jumlah kelompok.

2. Mengalokasikan data ke dalam kelompok dengan acak.

3. Hitung pusat kelompok (centroid/rata-rata) dari data yang ada di masing-masing kelompok dengan lokasi centroid setiap kelompok diambil dari rata-rata (mean) semua nilai data pada setiap fiturnya. Jika $M$ adalah jumlah data didalam sebuah kelompok, i adalah fitur ke-i didalam sebuah kelompok, dan $\mathrm{p}$ adalah dimensi data, maka persamaan untuk menghitung centroid fitur ke-i dapat menggunakan persamaan 1. Persamaan 1 dilakukan sebanyak $\mathrm{p}$ dimensi dari $\mathrm{i}=1$ sampai dengan $\mathrm{i}=\mathrm{p}$. Rumus persamaan 1 , yaitu :

$$
\text { .Ci } i=\frac{1}{M} \sum_{j=1}^{M} x_{j}
$$

Kemudian, alokasikan masing-masing data ke centroid rata-rata terdekat dengan beberapa cara yang dapat dilakukan untuk mengukur jarak data ke pusat kelompok. Salah satu cara yang dapat digunakan adalah dengan 
menggunakan Euclidean. Pengukuran jarak pada ruang jarak (distance space) Euclidean dapat dicari dengan menggunakan persamaan 2 . Rumus persamaan 2, yaitu :

$$
d=\sqrt{\left(x_{1}-x_{2}\right)^{2}+\left(y_{1}-y_{2}\right)^{2}}
$$

Pengalokasian kembali data ke dalam masingmasing kelompok dengan metode K-Means didasarkan pada perbandingan jarak antara data dengan centroid disetiap kelompok. Data dialokasikan secara ulang dan tegas ke kelompok yang memiliki cetroid jarak terdekat dari data. Menurut (MacQueen, 1967) pengalokasian dapat ditentukan menggunakan persamaan 3. Rumus persamaan 3, yaitu :

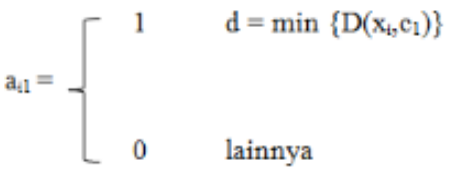

ai1 adalah nilai keanggotaan titik xi ke pusat kelompok c1, d adalah jarak terpendek dari data xi ke K kelompok setelah dibandingkan, dan c1 adalah centroid ke-1. Dalam metode K-Means, fungsi objektif digunakan untuk mmenentukan jarak dan nilai keanggotaan data dalam kelompok. Menurut (MacQueen, 1967), fungsi objektif dapat ditentukan menggunakan persamaan 4. Rumus persamaan 4, yaitu :

$$
J=\sum_{i=1}^{n} \sum_{i=1}^{k} a_{i c} D\left(x_{i}, c_{1}\right)^{2}
$$

$\mathrm{n}$ adalah jumlah data, $\mathrm{k}$ adalah jumlah kelompok, ai1 adalah nilai keanggotaan titik data xi ke kelompok cl yang diikuti. a mempunyai nilai 0 atau 1 . Jika data merupakan anggota suatu kelompok, nilai ai1 $=1$. Jika tidak, nilai ail $=0$.

4. Terakhir, jika ternyata masih ada data yang berpindah kelompok, masih ada perubahan nilai centroid di atas nilai ambang yang ditentukan, atau adanya perubahan nilai pada fungsi objektif yang digunakan masih di atas nilai ambang yang ditentukan, maka kembali ke langkah 3 (Dhuhita, 2015).

\section{HASIL DAN PEMBAHASAN}

\section{Enter Data in Tableau}

Memasukan data pada Tableau, berikut adalah tampilan data penduduk usia 5 tahun ke atas yang pernah mengakses internet dalam 3 bulan terakhir menurut provinsi dan kelompok umur 2017-2019:

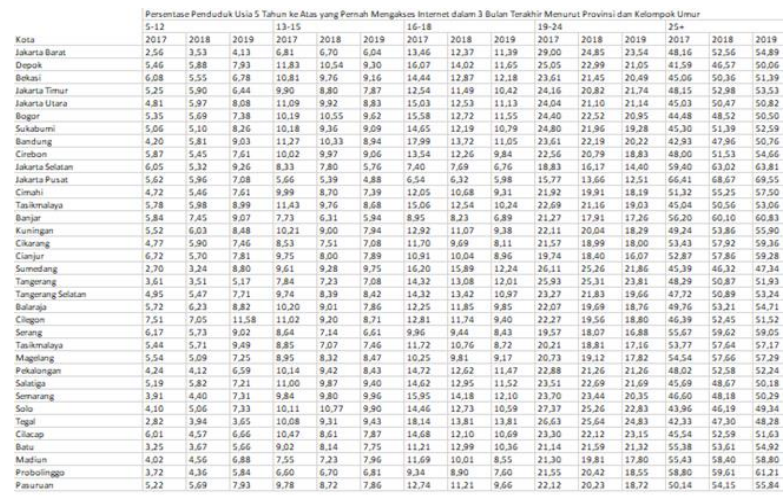

Sumber: (Evaristus Didik Madyatmadja et al, 2021)

Gambar 3. Data penduduk usia 5 tahun ke atas yang pernah mengakses internet dalam 3 bulan terakhir menurut provinsi dan kelompok umur 2017-2019

\section{Data Interpreter}

Data adalah catatan atas kumpulan fakta. Sementara interpretasi adalah pemberian kesan, pendapat, atau pandangan teoretis terhadap sesuatu. Interpretasi data merupakan sebuah bentuk dari kegiatan untuk melakukan penggabungan terhadap sebuah hasil dari analisis dengan berbagai macam pertanyaan, kriteria, maupun pada sebuah standar tertentu guna untuk dapat menciptakan sebuah makna dari adanya sebuah data yang dimana telah dikumpulkan.

Cara menggunakan data interpreter pada Tableau : Open Tableau, select Microsoft Excel in the list of connectors, and select the Dataset to clean Excel file.

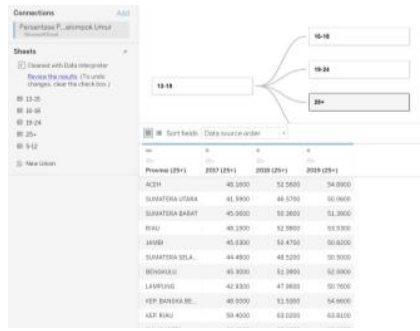

Sumber: (Evaristus Didik Madyatmadja et al, 2021) Gambar 4. Memasukan data pada Tableau 


\section{Dimensions and Measure}

Melakukan visualisasi data menggunakan Tableau dapat dilakukan pada lembar kerja dengan melakukan drag and drop dimensions atau measure yang ada pada row atau columns. Pada penelitian ini hanya menampilkan data penduduk usia 5 tahun ke atas yang pernah mengakses internet dalam 3 bulan terakhir menurut provinsi dan kelompok umur 2017 - 2019

Berikut adalah pemilihan dimensions dan measure yang dilakukan :

a. Drag Provinsi pada bagian column

b. Drag tahun yang akan dibandingkan pada measure values

c. Drag Provinsi pada Filters dan pilih daerah yang ingin dipilih

d. Drag Measure Names pada Marks dan pilih warna yang diinginkan

e. Drag Measure Names di columns

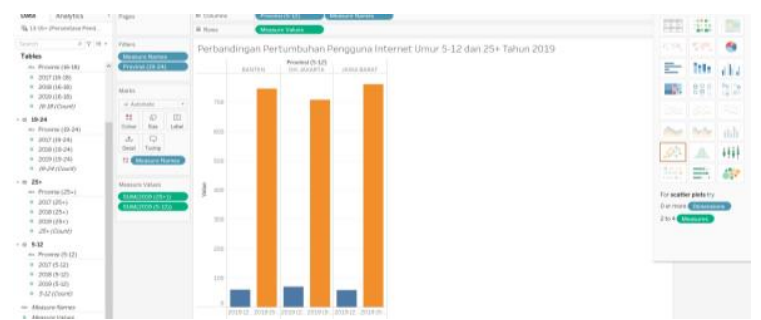

Sumber: (Evaristus Didik Madyatmadja et al, 2021)

Gambar 4. Menentukan dimensions dan measure

\section{Visualization Result}

Langkah berikutnya yaitu membandingkan pertumbuhan pengguna internet setiap tahunnya. Untuk itu dibuatlah data visualisasi berbentuk side-by-side chart agar hasilnya dapat dibandingkan dengan lebih mudah.
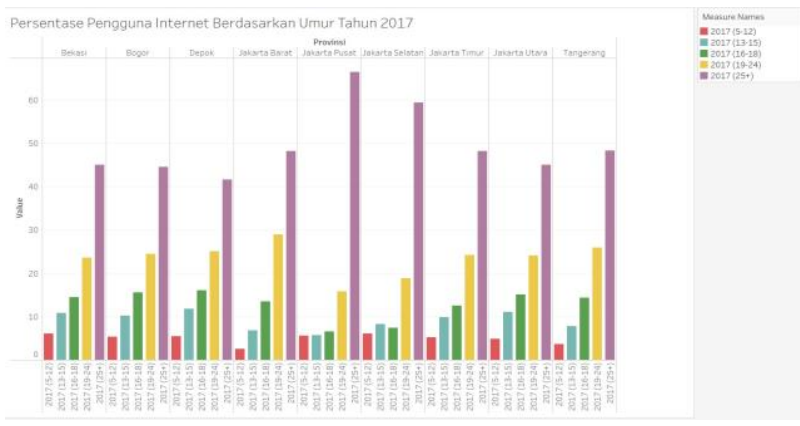

Sumber: (Evaristus Didik Madyatmadja et al, 2021) Gambar 5. Perbandingan Pertumbuhan Pengguna Internet Berdasarkan Umur Tahun 2017
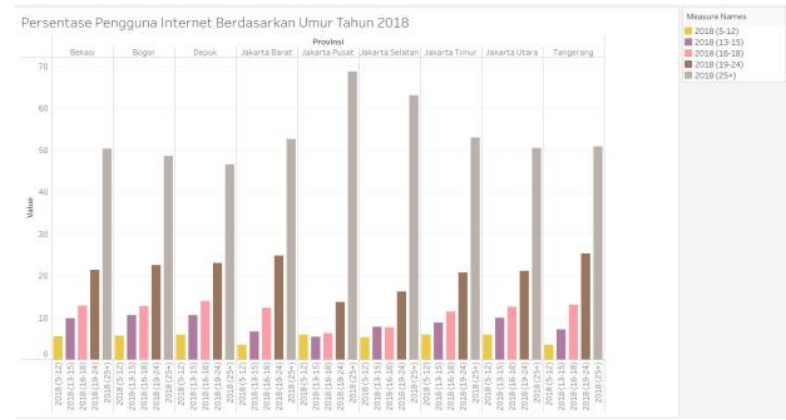

Sumber: (Evaristus Didik Madyatmadja et al, 2021)

Gambar 6. Perbandingan Pertumbuhan Pengguna

Internet Berdasarkan Umur Tahun 2018

Pada gambar 6, kita dapat menyimpulkan pada tahun 2018 di Kota Bekasi penggunaan internet paling banyak digunakan oleh masyarakat yang berumur 25 tahun keatas dengan value diatas $50 \%$, posisi kedua tertinggi yaitu pengguna yang berumur 19-24 dengan value diatas $20 \%$, di posisi ketiga yaitu pengguna yang berumur 16-18 tahun dengan value diatas $10 \%$, posisi keempat yaitu pengguna yang berumur 13-15 tahun dengan value $10 \%$, dan posisi terendah yaitu pengguna yang berumur 5-12 tahun dengan value dibawah $10 \%$.

\section{KESIMPULAN}

Internet adalah suatu jaringan komunikasi yang memiliki fungsi untuk menghubungkan antara satu media elektronik dengan media elektronik yang lain dengan cepat dan tepat. Selain itu, kemajuan dalam bidang teknologi informasi merupakan suatu hal yang akan terus terjadi dan berkembang. Melalui kemajuan teknologi informasi dengan sebaran performa internet yang merata di seluruh daerah maka penyampaian informasi terkait dengan pemerintahan negara dapat tersampaikan dengan lebih mudah dan cepat kepada masyarakat. Seiring berkembangnya zaman informasi dapat dengan mudah didapatkan melalui smartphone. Oleh karena itu, pemerataan internet di seluruh daerah di Indonesia perlu menjadi perhatian pemerintah untuk ditindaklanjuti.

Dari penelitian ini dapat disimpulkan bahwa dalam kurun waktu 3 tahun, yaitu 2017, 2018, dan 2019 pada Kota Bekasi, Bogor, Depok, Jakarta Barat, Jakarta Pusat, Jakarta Selatan, Jakarta Timur, Jakarta Utara, dan Tangerang terkait penggunaan internet paling banyak digunakan oleh masyarakat yang berusia 25 tahun keatas dan yang terendah yaitu masyarakat yang berusia 5-12 tahun. Kemudian dari ketiga provinsi tersebut yang pertumbuhan pengguna internetnya paling rendah adalah Kota Depok. 
Sehingga berdasarkan hasil visualisasi data dari perbandingan 3 grafik di atas, pemerintah diharapkan untuk dapat memberikan perhatian lebih pada Kota Depok dan untuk pemerataan internet agar penyebaran informasi dapat berjalan dengan maksimal karena penyebaran informasi dengan menggunakan internet akan lebih mudah dan jangkauannya juga semakin luas, terlebih lagi Kota Depok merupakan salah satu dari tiga kota metropolitan dan penyokong ibukota DKI Jakarta.

\section{DAFTAR PUSTAKA}

Abyadl, M. F., Sumarno, -, \& Indrianawati, -. (2018). Evaluasi Pembangunan Sistem Visualisasi Data (Studi Kasus: Pengelolaan Data pada Kementerian Dalam Negeri Indonesia). Reka Geomatika, 2016(2), 80-89. https://doi.org/10.26760/.v2016i2.1855

Arifin, Z., \& Sugiharto, A. (2013). Rancang Bangun Sistem Business Intelligence Universitas Sebagai Pendukung Pengambilan Keputusan Akademik. Jurnal Sistem Informasi Bisnis, 3(1), 30-40. https://doi.org/10.21456/vol3iss1pp30-40

Ariyanti, S. (2015). Studi Perencanaan Jaringan Long Term Evolution Area Jabodetabek Studi Kasus PT. Telkomsel. Buletin Pos Dan Telekomunikasi, 12(4), 255. https://doi.org/10.17933/bpostel.2014.120402

Asroni, R. A. (2015). Penerapan Metode K-Means Untuk Clustering Mahasiswa Berdasarkan Nilai Akademik Dengan Weka Interface Studi Kasus Pada Jurusan Teknik Informatika UMM Magelang. Ilmiah Semesta Teknika, 18(1), 76-82. https://doi.org/10.1038/hdy.2009.180

Basis Data Pusat Pengembangan Kawasan Perkotaan. (2015). Metropolitan Jakarta, Bogor, Depok, Tangerang, Puncak, Cianjur. Bpiw.Pu.Go.Id.

Budiyantara, A., Irwansyah, I., Prengki, E., Pratama, P. A., \& Wiliani, N. (2020). Komparasi Algoritma Decision Tree, Naive Bayes Dan K-Nearest Neighbor Untuk Memprediksi Mahasiswa Lulus Tepat Waktu. JITK (Jurnal Ilmu Pengetahuan Dan Teknologi Komputer), 5(2), 265-270. https://doi.org/10.33480/jitk.v5i2.1214

Center, C. T. (2015). Tableau Classroom Training. Cybertrend Training Center.

Dhuhita, W. (2015). Clustering Menggunakan Metode K-Mean Untuk Menentukan Status Gizi Balita. Jurnal Informatika Darmajaya, 15(2), 160-174.

Evaristus Didik Madyatmadja, An Nisa'a Nuramalia, L. K., \& Syahlaa Perdina Jamil, W. K. (2021). Data Visualization of Internet Usage In The Jabodetabek Area.
Hartama, D. (2018). Analisa Visualisasi Data Akademik Menggunakan Tableau Big Data. Jurasik (Jurnal Riset Sistem Informasi Dan Teknik Informatika), 3(3), 46. https://doi.org/10.30645/jurasik.v3i0.65

Herliana, A., \& Rasyid, P. M. (2016, A. (2016). Sistem Informasi Monitoring Pengembangan Software Pada Tahap Development Berbasis Web. Jurnal Informatika, 43.

Irmayani, W. (2021). Visualisasi Data Pada Data Mining Menggunakan Metode Klasifikasi. Ix(I), 68-72.

Kristina, E. (2015). Pola Penggunaan Internet Oleh Kalangan Remaja Di Kabupaten Semarang. Pola Penggunaan Internet Oleh Kalangan Remaja Di Kabupaten Semarang Ester Krisnawati, 319-350.

Noveriyanto, B., Nisa, L. C., Bahtiar, A. S., Sahri, S., \& Irwansyah, I. (2018). E-Government Sebagai Layanan Komunikasi Pemerintah Kota Surabaya (Studi Kematangan e-government Sebagai Layanan Komunikasi Government to Government, Government to Citizen, Government to Business). Profetik: Jurnal Komunikasi, 11(1), 37. https://doi.org/10.14421/pjk.v11i1.1371

Qolbi, A. A. (2016). Penerapan Metode Clustering KMeans Terhadap Dosen Berdasarkan Publikasi Jurnal Nasional dan Internasional. 1-69.

Rahmawati, L., Widya Sihwi, S., \& Suryani, E. (2016). Analisa Clustering Menggunakan Metode KMeans Dan Hierarchical Clustering (Studi Kasus : Dokumen Skripsi Jurusan Kimia, Fmipa, Universitas Sebelas Maret). Jurnal Teknologi \& Informasi ITSmart, 3(2), 66. https://doi.org/10.20961/its.v3i2.654

Richard Qi Li. (2020). Overview of Data Visualization. In Embodying Data. https://doi.org/10.1007/978981-15-5069-0_2

Rustiadi, E., Pribadi, D. O., Pravitasari, A. E., Indraprahasta, G. S., \& Iman, L. S. (2015). Jabodetabek Megacity: From City Development Toward Urban Complex Management System. July 2016, 421-445. https://doi.org/10.1007/9784-431-55043-3_22

Saepuloh, D. (2020). Visualisasi Data Covid 19 Provinsi Dki Jakarta Menggunakan Tableau Data Visualization Of Covid 19 Province Dki Jakarta Using Tableau (pp. 55-64). Jurnal Riset Jakarta.

Yusup, P. M., Komariah, N., Prahatmaja, N., \& CMS, S. (2019). Pemanfaatan Internet Untuk Penghidupan Di Kalangan Pemuda Pedesaan. Baca: Jurnal Dokumentasi Dan Informasi, 40(2), 217. https://doi.org/10.14203/j.baca.v40i2.491 
VOL. 7 No. 1 Juni 2021

P-ISSN : 2460-2108

E-ISSN :2620-5181
INFOTECH: JOURNAL OF TECHNOLOGY INFORMATION

DOI: https://doi.org/10.37365/jti.v7i1.108 